\title{
Effects of Herbal-Plant Supplementation During Pregnancy on Ewes' Blood Parameters and Lambs' Birth Weight
}

\author{
AO Hendawy ${ }^{1,2 *}$, MM Mansour ${ }^{1}$, MS Moharam ${ }^{1}$ and ANM Nour El Din ${ }^{3}$ \\ ${ }^{1}$ Department of Animal and Poultry Production, Faculty of Agriculture, Damanhour University, Egypt. \\ ${ }^{2}$ Department of Biological Production, Tokyo University of Agriculture and Technology, Tokyo, Japan. \\ ${ }^{3}$ Department of Animal and Fish Production, Faculty of Agriculture (El-Shatby), Alexandria University, Egypt.
}

*Corresponding author: AO Hendawy Department of Animal and Poultry Production, Faculty of Agriculture, Damanhour University, Damanhour, Egypt.
Received Date: June 11, 2020

Published Date: July 07, 2020

\begin{abstract}
The objective of this study was to examine the effect of dietary supplementation of Nigella sativa seeds and Zingiber officinale powder on blood hematological parameters, biochemical parameters, and oxidative stress markers in pregnant ewes as well as on lambs' birth weight. Fifteen pregnant crossbred ewes aged 3-5 years old weighing an average of $48.5 \pm 2.03 \mathrm{Kg}$, 8 weeks before expected calving date, were randomly divided into 3 groups: one control and 2 experimental groups. Ewes in the control group were fed basal diet only, while ewes in experimental groups were fed basal diet supplemented with Nigella sativa seeds or Zingiber officinale powder at a concentration of $5 \mathrm{~g}$ a day/animal until parturition. Blood samples were withdrawn biweekly until parturition. Counts of white blood cells were lower in Nigella sativa seeds treated animals compared with ewes in other groups. Total protein and glucose levels increased $(\mathrm{P}<0.05)$ in ewes fed herbal plants compared with the control while cholesterol and triglyceride levels decreased $(\mathrm{P}<0.05)$ in the treated animals compared with the control. Dietary supplementation with medicinal plants reduced malondialdehyde concentration while total antioxidant capacity increased; however, this increase was not significant $(\mathrm{P}<0.05)$. There was an insignificant improvement in lambs' birth weight of the treated animals compared with the control group. Use of medicinal plants as feed additive to ewes' diet may improve blood biochemical parameters and reduce oxidative stress at late gestation period. These effects are likely to enhance animal performance. Larger number of replicates on the tolerance levels of Nigella sativa seeds and Zingiber officinale concentrations in the dietary treatment of ewes should be further studied.
\end{abstract}

Keywords: Antioxidant; Birth weight; Ewe; Nigella sativa; Zingiber officinale

\section{Introduction}

The ban set on antibiotics use to reduce energy loss and enhance productivity in livestock industry forced those concerned with animal production to search for safer and better alternatives $[1,2]$. In recent years, herbal plants have gained much attention as alternative growth promoters to antibiotic. Various medicinal plants and their extracts have been used as feed additives due to their various health-promoting effects such as being anti-oxidative, antimicrobial, anti-inflammatory, and growth-promoting [3-5].
Previous studies have reported that medicinal plants and their extracts may be included in ruminant diets to improve nutrient digestibility, rumen fermentation, immune function, milk production, and composition $[6,7]$.

Nigella sativa is a small aromatic black seed slightly smaller than the sesame seed. It is commonly known as black seed and belongs to the botanical family of the Ranunculaceae, which grows in countries bordering the Mediterranean basin 
and other places of similar climates [8-10]. This herb has long been used in traditional medicine due to its amazing pharmacological properties, and it also enjoys a rich historical and religious background [11]. Nigella sativa seeds contain many active components includingthymoquinone, thymohydroquinone, dithymoquinone, nigellone, melanthin, nigilline nigelamine, damascenone, $\mathrm{p}$-cymene, and pinene, in addition to a large number of minerals (e.g., calcium, phosphorus, potassium, magnesium, iron, cobalt, and zinc) and vitamins such as A, B, C, D and E [12-14]. Seeds of Nigella sativa represent a major source of fixed and essential oils, proteins, saponins, polyphenols, alkaloids, and flavonoids. Previous reports suggest that thymoquinone (an alkaloid), nigellone (a carbonyl polymer of thymoquinone) and fixed oils are the most active component ingredients in Nigella sativa [8-15]. Nigella sativa seeds have many beneficial properties as antitumor, antidiabetic, anti-asthmatic antihypertensive, antioxidative, antimicrobial (antibacterial, antifungal and anthelminthic), anti-inflammatory, analgesic, antipyretic, diuretic, carminative, laxative, antimicrobial and antineoplastic activity $[9,16,17]$.

Zingiber officinale is a rhizome (ginger root) that is widely used as a spice and a herbal remedy for a large number of diseases for many years [18,19]. Zingiber officinale contains several active compounds such as gingerol, gingerdiol, and gingerdione [19]. These compounds possess strong antioxidant, immunomodulatory, anti-cancer, anti-inflammatory, anti-apoptotic, anti-hyperglycemic, anti-lipidemic, antifungal, and anti-stress activities [5,20,21].

The objective of the present study was to investigate the effect of dietary supplementation of Nigella sativa seeds and Zingiber officinale powder on blood hematological parameters, biochemical parameters, and oxidative stress markers in pregnant ewes as well as lambs birth weight. We hypothesized that ewes supplemented by herbal plants will exhibit better blood parameters and oxidative status compared with the control counterparts.

\section{Materials and Methods}

\section{Animals and managements}

All procedures were approved by The Ethics of Animal Experiments Committee, Damanhour University. The current study was carried out at the experimental farm of the Faculty of Agriculture, Damanhour University located in Al-Bostan. Fifteen pregnant crossbred (Rahmany $\times$ Balady) ewes, aged 3-5 years old and weighing an average of $48.5 \pm 2.03 \mathrm{Kg}$, were divided into three groups; one control and two experimental groups. Ewes fed like those in our previous report [7]. Briefly, ewes in all groups were fed a basal diet comprising wheat straw and concentrate feed mixture of $55 \%$ yellow corn grain, $20 \%$ wheat bran, $12.5 \%$ cotton seed meal, $10 \%$ soy bean meal, $1 \%$ sodium chloride, $1.4 \%$ lime stone, and $0.1 \%$ avimix mineral mixture. Each $1 \mathrm{~kg}$ of avimix mineral mixture (AGRIVET) consisted of manganese sulphate (16.66 g), zinc sulphate (20 g), iron sulphate (10 g), potassium iodide ( $0.83 \mathrm{~g})$, cobalt chloride $(0.17 \mathrm{~g})$, sodium selinite $(0.066 \mathrm{~g})$, and calcium carbonate $(952.27$ g). While the control group fed the basal diet only, the 2 experimental groups received $5 \mathrm{~g} / \mathrm{h} / \mathrm{d}$ of either Nigella sativa seeds or Zingiber officinale powder. Concentrate feed mixture was offered two times a day at a rate of $2.5 \%$ of animal weight while wheat straw and water were offered ad libitum. We analyzed wheat straw, concentrated feed mixture, Nigella sativa seeds and Zingiber officinale powder for moisture, ash, crude protein, ether extract, crude fiber and nitrogen free extract according to the Official Methods of AOAC [22]. Cell wall constituents were estimated according to the method described by Van Soest [23]. Non fibrous carbohydrates were calculated according to Calsamiglia [24]. (Table 1) presents data resulting from these analyses.

Table 1: Chemical composition and cell wall constituents of concentrate feed mixture, wheat straw, Nigella sativa seeds, and Zingiber officinale fine powder (on dry matter basic) used in this experiment.

\begin{tabular}{|c|c|c|c|c|}
\hline Item & Concentrate feed mixture & Wheat straw & Nigella sativa seeds & Zingiber officinale \\
\hline Dry matter & 88.97 & 91.36 & 93.72 & 89.57 \\
\hline Organic matter & 93.73 & 92.31 & 95.81 & 92.26 \\
\hline Crude protein & 15.27 & 2.68 & 25.58 & 7.81 \\
\hline Crude fiber & 9.27 & 39.95 & 4.4 & 7.42 \\
\hline Ether extract & 2.37 & 1.77 & 10.52 & 6.12 \\
\hline Nitrogen free extract & 66.82 & 47.91 & 55.31 & 70.91 \\
\hline Ash & 6.27 & 7.69 & 4.19 & 7.74 \\
\hline \multicolumn{5}{|c|}{ Cell wall constituents } \\
\hline Neutral detergent fiber & 35.92 & 76.42 & - & - \\
\hline Acid detergent fiber & 17.71 & 52.61 & - & - \\
\hline Hemicellulose & 18.21 & 23.81 & - & - \\
\hline Non-fibrous carbohydrate 1 & 40.17 & 11.44 & - & - \\
\hline
\end{tabular}

\section{Sampling and measurements}

\section{Blood analysis}

Blood samples were collected biweekly until parturition from each group (in the morning before feeding). Samples were obtained from the jugular vein in two clean tubes, one containing EDTA disodium salt as an anticoagulant for hematological parameters while the other tube contained no anticoagulant since blood biochemical parameters were estimated from the serum. Samples were immedi- 
ately kept in an ice tank. Blood samples were centrifuged at (3500 rpm) for 15 minutes to separate the serum, which was stored at $\left(-20{ }^{\circ} \mathrm{C}\right)$ until analysis.

The concentrations of total protein, glucose, total cholesterol, triglyceride, total antioxidant capacity, and malondialdehyde in serum were analyzed by assay kits according to the manufacturer's instructions (Biodiagnostic Company, Giza, Egypt). While hematological parameters such as red blood cells (RBCs), hemoglobin (Hb), packed cell volume (PCV), mean cell volume (MCV), mean cell hemoglobin (MCH), mean cell hemoglobin concentration (MCHC), platelets, and white blood cells (WBCs) were determined in fresh blood through an automatic blood analyzer (EXIGO VET, Boul Medical AB, Spanga, Sweden).

\section{Statistical analysis}

Data were statistically analyzed using One-Way Analysis of Variance (ANOVA) test 'Duncan's Multiple Range Test' with alpha at the significance level of 0.05. Data are presented as means with standard error. The collected data were performed using PASW statistic 18.0 (SPSS, Inc., Chicago, IL, USA).

\section{Results and Discussion}

Table 2: Effect of Nigella sativa seeds and Zingiber officinale powder supplementation on blood hematological parameters of pregnant ewes.

\begin{tabular}{|c|c|c|c|c|}
\hline Item & Control & Nigella sativa & Zingiber officinale & SEM \\
\hline Red blood cells (x 106/ $\mu \mathrm{L})$ & 9.22 & 8.53 & 9.59 & 0.26 \\
\hline Hemoglobin (g/dl) & 9.04 & 9.24 & 9.63 & 0.13 \\
\hline Packed cell volume (\%) & 21.83 & 23.03 & 24.7 & 0.68 \\
\hline Mean cell volume (fL) & 25.68 & 27.43 & 25.82 & 0.53 \\
\hline Mean cell hemoglobin (pg) & 9.98 & 10.65 & 10.1 & 0.17 \\
\hline Mean cell hemoglobin concentration (g/dL) & 39.07 & 38.88 & 39.25 & 0.36 \\
\hline Platelets $(\mathrm{x} 103 / \mu \mathrm{L})$ & 132.33 & 173.2 & 151 & 32.17 \\
\hline White blood cells (x 103/ $\mu \mathrm{L})$ & $6.90 \mathrm{a}$ & $4.78 \mathrm{~b}$ & $6.48 \mathrm{a}$ & 0.65 \\
\hline $\begin{array}{l}\text { a,b Means with different superscripts in the same row } \\
\text { nificantly different at }(\mathrm{P}<0.05) .\end{array}$ & & & & \\
\hline
\end{tabular}

Ewes fed Nigella sativa seeds had significantly lower WBCs count compared with ewes fed Zingiber officinale powder or basal diet. Meanwhile, there were no significant changes in the percentages of $\mathrm{Hb}, \mathrm{PCV}, \mathrm{MCV}$, and MCHC, as well as counts of RBCs and platelets (Table 2). Findings from former studies are mixed. Consistent with our results, Abd El-Halim [25] reported significantly $(\mathrm{P} \leq 0.05)$ lower total WBCs count in growing lambs fed Nigella sativa oil (NSO) than the control. Meanwhile RBCs count transiently decreased at $2 \mathrm{wk}$, but it significantly increased $(\mathrm{P} \leq 0.05)$ after $6 \mathrm{wk}$. They found no significant differences in the percentages of PCV, MCV, MCH, and MCHC among NSO animals throughout their experiment [25]. On the other hand, Hendawy. [7] reported that counts of RBCs and WBCs significantly increased in lactating ewes fed Zingiber officinale powder compared with lactating ewes fed basal diet or Nigella sativa seeds. In contrast, MCH was higher in both the Nigella sativa seeds and control groups than the Zingiber officinale powder group $(\mathrm{P}<0.05)$. While, there were no significant changes in the percentages of $\mathrm{Hb}, \mathrm{PCV}, \mathrm{MCV}, \mathrm{MCHC}$, and platelets. Unlike our findings, EL-Ghousein [26] reported no changes in RBCs, $\mathrm{Hb}$, and WBCs in ewes fed $10 \mathrm{~g} / \mathrm{h} / \mathrm{d}$ Nigella sativa seed. Still the observed variation in these parameters can be due to the variation of preparation, doses, duration of supplementation, animal species, sex, age, and factors that affect their absorption from the gut and their bioavailability.

The concentration of serum total protein and glucose increased $(\mathrm{P}<0.05)$ in animals treated with medicinal plants compared with the control animals. On the contrary, serum levels of total cholester- ol and triglyceride were lower in the treatment groups compared with the control group (Figure 1A and 1B). Enhancement of serum protein expressed animals treated with Nigella sativa and Zingiber officinale is congruent with reports of several previous studies. In accordance, Saleh [27] reported that supplementing lactating ewes with Nigella sativa seeds increased $(\mathrm{P}<0.05)$ serum protein compared with ewes fed basal diet. In the same line, Allak [28] reported that Ossimi rams fed Nigella sativa seeds or Zingiber officinale had significantly $(\mathrm{P} \leq 0.05)$ higher serum protein compared with control animals. In agreement, Khattab [29] confirmed that buffalo supplemented with Nigella sativa seed oil exhibited increased protein anabolism due to higher protein digestibility, which resulted in higher blood plasma total protein-the main contributor to increased tissue protein biosynthesis. In the same regard, Habeeb and El-Tarabany [30] recorded that Nigella sativa additive to the diet of Zaraibi kids significantly increased plasma total proteins and globulin. In contrast, Ibrhim [31] reported no changes in total protein level of lactating Awassi ewes supplemented with Zingiber officinale extract by $2 \mathrm{ml} / 2$ liter per day in drinking water. It is likely that herbal plants increase serum protein by creating favorable rumen conditions that promote microbial activity toward the best utilization of ruminal ammonia and the most efficient conversion of dietary substrates into microbial protein-feed the microbiome and let the microbiome feed the animal [6].

The reductions in total cholesterol and triglyceride levels observed following ewe's treatment with Nigella sativa seeds and Zingiber officinale powder in the present experiment (Figure 1C and 
1D) are consistent with finding reported by many other studies. Consistent with our findings, Allak [28] noted that Ossimi rams fed Nigella sativa seeds and Zingiber officinale herbs had significantly $(\mathrm{P} \leq 0.05)$ lower cholesterol and triglyceride levels compared with control animals. In the same line, Saleh reported decreased triglyceride and total cholesterol $(\mathrm{P}<0.05)$ in lactating ewes supplemented with Nigella sativa seeds compared with ewes on basal diet
[27]. Alike, Khattab et al. reported decreased cholesterol level in buffalo fed NSO [29]. Similar effects of Nigella sativa were obtained in growing Zaraibi goats [30]. On the contrary, Retnani [32] reported no change in blood glucose and triglyceride levels of lambs fed diet containing $10 \%$ or $20 \%$ Nigella sativa. The cholesterol lowering effect of both Nigella sativa seeds and Zingiber officinale may be attributable to their high contents of unsaturated fatty acids [29].

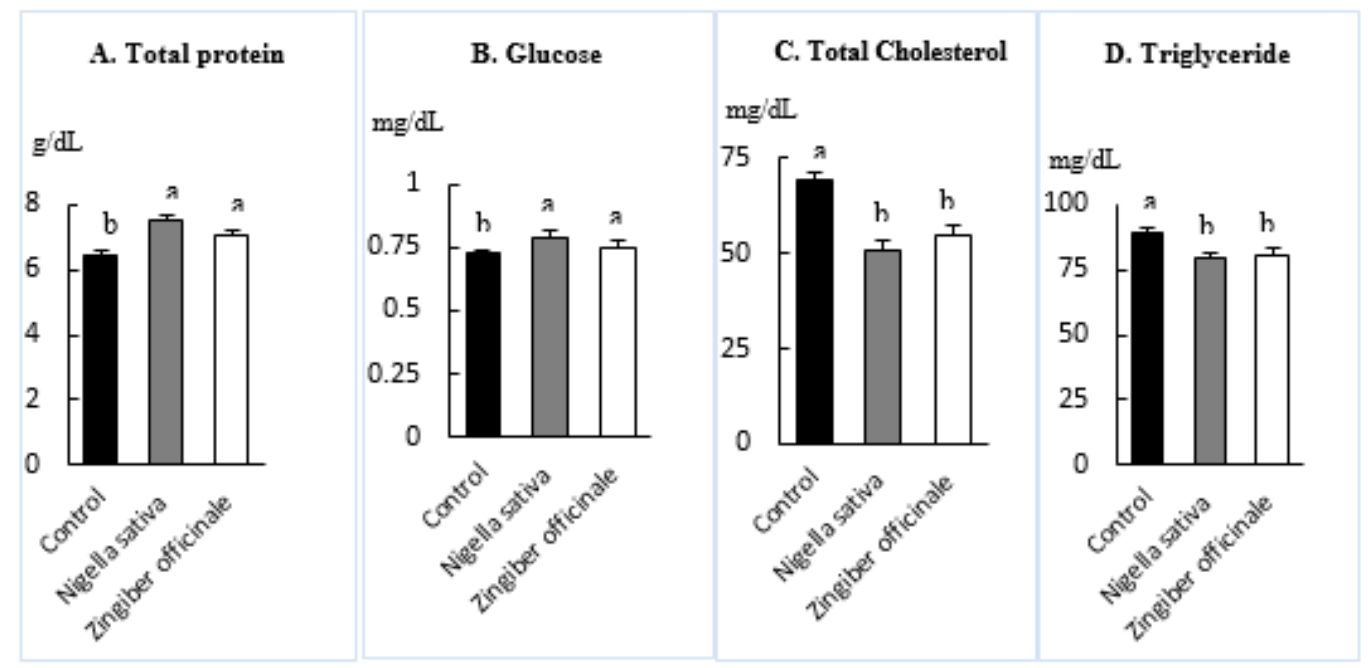

Figure1: Effect of Nigella sativa seeds and Zingiber officinale fine powder supplementation on biochemical composition of the serum in pregnant ewes. Bars indicate the SEM; a, b Different letters indicate significant differences, $\mathrm{P}<0.05$.

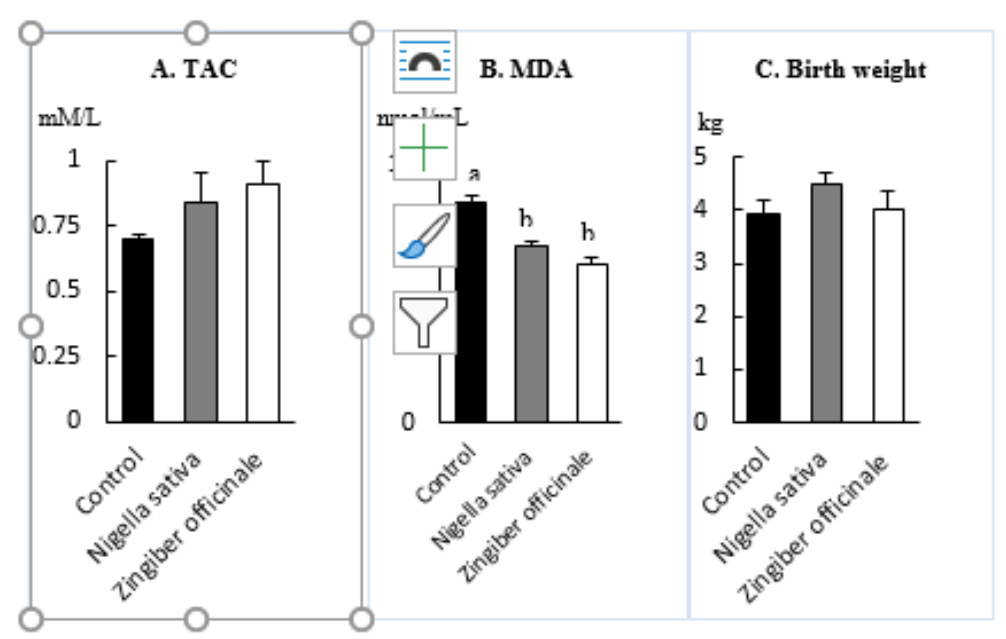

Figure2: Effect of Nigella sativa seeds and Zingiber officinale fine powder supplementation on oxidative status including total antioxidant capacity (TAC; Fig 2A) and malondialdehyde (MDA; Fig 2B) in pregnant ewes and their lambs' birth weight (Fig 2C). Bars indicate the SEM; $a, b$ Different letters indicate significant differences, $P<0.05$.

The present research revealed significant drop in serum concentration of malondialdehyde in pregnant ewes fed medicinal plants-supplemented diets compared with their control counterparts. Moreover, Nigella sativa seeds and Zingiber officinale treatments increased total antioxidant capacity; however, that increase was insignificant (Figure 2A and 2B). In accordance, El-Far [5] reported that supplementing sheep with Nigella sativa seeds and Zingiber officinale powder significantly decreased malondialde- hyde and significantly increased serum total antioxidant capacity and blood antioxidant enzyme e.g., catalase, glutathione peroxidase, glutathione S-transferase and total superoxide dismutase $(\mathrm{P}<$ $0.05)$. Such enzymes rapidly convert the corrosive superoxide $\left(\mathrm{O}_{2}{ }^{--}\right)$ to less dangerous $\mathrm{H}_{2} \mathrm{O}_{2}$, which is further degraded to water $[33,34]$. Another study revealed no effect of herbal blend additives on levels of malondialdehyde and total antioxidant capacity in plasma or rumen fluid [31]. Altogether, Nigella sativa seeds and Zingiber offi- 
cinale powder seem to be efficient in counteracting oxidative stress via enhancement of the production of internal antioxidants.

We recorded an increase in lambs birth weight of ewes supplemented with herbal plants-rich diet; nonetheless, that increase was not significant (Figure 2C). Consistent with this report, Dudkoa et al. indicated that enriching sheep meal with a blend of essential oil in $O$. vulgare and Citrus spp. caused no significant difference lambs' body weight at birth [35]. On the other side, Sahoo et al. reported that supplementing Black Bengal goats with polyherbal immunomodulator (immu-21) during the last month of pregnancy resulted in several positive effects: significantly higher birth weights, absence of kid mortality, and heightened concentrations of blood protein and colostrum immunoglobulin. The researchers concluded that polyherbal immunomodulator supplementation to goats during late pregnancy and to kids during early growth periods is much more beneficial than solo administration at either stage [36]

Effects of herbal plants on lamb birth weight and growth in the first few weeks of life speak for their multiple effects on mother ewes-increased protein synthesis, immune enhancement, and improved redox state.

\section{Conclusion}

In conclusion, results of this study highlight a positive effect of herbal-plant dietary supplementation to pregnant ewes on some blood parameters as well as markers of oxidative stress. Late gestation and early post parturition represent a time of great physiological stress, which is characterized by increased oxidative stress. Therefore, it is recommended to supplement ewes during these stages with Nigella sativa seeds and Zingiber officinale powder to increase the activity of their antioxidant system. It will be beneficial if several large sample size studies were performed as replication of the current study on different farm animals to check the effect of herbal plants.

\section{Acknowledgement}

None.

\section{Conflicts of Interest}

None.

\section{References}

1. Mcgrath J, Duval SM, Tamassia LFM, Kindermann M, Stemmler RT, et al. (2018) Nutritional strategies in ruminants: A lifetime approach. Res. Vet. Sci 116: 28-39.

2. Hendawy AO, Shiraishi M, Takeya H, Sugimura S, Miyanari S, et al. (2019) Effects of 5-aminolevulinic acid supplementation on milk production, iron status, and immune response of dairy cows. J. Dairy Sci 102(12): 11009-11015.

3. Özer H, Sökmen M, Güllüce M, Adigüzel A, Şahin F, et al. (2007) Chemical composition and antimicrobial and antioxidant activities of the essential oil and methanol extract of hippomarathrum microcarpum (bieb.) From Turkey. J. Agric. Food Chem 55(3): 937-942.

4. Yang Y, Zhang Z, Li S, Ye X, Li X, et al. (2014) Synergy effects of herb extracts: Pharmacokinetics and pharmacodynamic basis. Fitoterapia 92: 133-147.
5. El-far A, Kamal E, Moharam MS (2014) Antioxidant and antinematodal effects of Nigella sativa and Zingiber officinale supplementations in ewes. Int. J. Pharm. Sci. Rev. Res 26: 222-227.

6. Kholif SM, Morsy TA, Abdo MM, Matloup OH, Abu El-Ella AA (2012) Effect of supplementing lactating goats rations with garlic, cinnamon or ginger oils on milk yield, milk composition and milk fatty acids profile. J. Life Sci 4: 27-34.

7. Hendawy AO, Mansour MM, Nour El-Din ANM (2019) Effects of medicinal plants on haematological indices, colostrum, and milk composition of ewes. J. Vet. Med. Anim. Sci 2(1): 1008.

8. Sideeg RM (2000) Effect of dietary vitamin A and Nigella sativa on the performance of broiler chicks 31 .

9. Al-naqeep G, Al-zubairi AS, Ismail M, Amom ZH, Esa NM (2011) Antiatherogenic potential of Nigella sativa seeds and oil in diet-induced hypercholesterolemia in rabbits. Evidence-Based Complement. Altern. Med.

10. Abbas TE, Ahmed ME (2010) Effect of supplementation of Nigella sativa seeds to the broiler chicks diet on the performance and carcass quality. Int. J. Agric. Sci 2: 9-13.

11. Parhizkar S, Abdul Latiff L, Abdul Rahman S, Dollah MA, Parichehr H (2011) Assessing estrogenic activity of Nigella sativa in ovariectomized rats using vaginal cornification assay. African J. Pharm. Pharmacol 5: 137-142.

12. Khan SH, Ansari J, Haq A, Abbas G (2012) Black cumin seeds as phytogenic product in broiler diets and its effects on performance, blood constituents, immunity and caecal microbial population. Ital. J. Anim. Sci 90(11): 2500-2510.

13. Rahman M, Kim S (2016) Effects of dietary Nigella sativa seed supplementation on broiler productive performance, oxidative status and qualitative characteristics of thighs meat. Ital. J. Anim. Sci 15: 241247.

14. Cheikh-Rouhou S, Besbes S, Hentati B, Blecker C, Deroanne C, et al. (2007) Nigella sativa L.: Chemical composition and physicochemical characteristics of lipid fraction. Food Chem 101(2): 673-681.

15. Ekanem JT, Yusuf OK (2008) Some biochemical and haematological effects of black seed (Nigella sativa) oil on T. brucei-infected rats. African J. Biomed. Res 11: 79-85.

16. Aydin R, Karaman M, Cicek T, Yardibi H (2008) Black cumin (Nigella sativa L.) supplementation into the diet of the laying hen positively influences egg yield parameters, shell quality, and decreases egg cholesterol. Poult. Sci 87(12): 2590-2595.

17. Bashandy AES (2007) Effect of fixed oil of Nigella sativa on male fertility in normal and hyperlipidemic rats. Int. J. Pharmacol 3(1): 27-33.

18. Cornale P, Tarantola M, Lussiana C, Tassone S, Castellina C, et al. (2011) Effects of ginger (Zingiber officinale) and European stoneseed (Lithospermum officinale) extracts on performance, meat quality and fatty acid composition of finishing bulls. Joumal Anim. Vet. Adv 10(9): 1127-1132.

19. Zhang GF, Yang ZB, Wang Y, Yang WR, Jiang SZ, et al. (2009) Effects of ginger root (Zingiber officinale) processed to different particle sizes on growth performance, antioxidant status, and serum metabolites of broiler chickens. Poult. Sci 88(10): 2159-2166.

20. Kim E, Min J, Kim T, Lee S, Yang H, et al. (2005) [6]-Gingerol, a pungent ingredient of ginger, inhibits angiogenesis in vitro and in vivo. Biochem. Biophys. Res. Commun 335: 300-308.

21. Nanjundaiah SM, Annaiah HNM, Dharmesh SM (2011) Gastroprotective effect of ginger rhizome (Zingiber officinale) extract: Role of gallic acid and cinnamic acid in $\mathrm{H}+, \mathrm{K}+-\mathrm{ATPase} / \mathrm{H}$. pylori inhibition and antioxidative mechanism. Evidence-Based Complement. Altern. Med 1-13.

22. Latimer GW. AOAC International. Official methods of analysis of AOAC International. 19th ed. Gaithersburg, MD, USA: AOAC International. 2012. 
23. Van Soest PJ, Robertson JB, Lewis BA (1991) Methods for dietary fiber neutral detergent fiber, and nonstarch polysaccharides in relation to animal nutrition. J. Dairy Sci 74(10): 3583-3597.

24. Calsamiglia S, Stern MD, Firkins JL (1995) Effects of protein source on nitrogen metabolism in continuous culture and intestinal digestion in vitro. J. Anim. Sci 73(6): 1819-27.

25. Abd El-Halim MI, El-Bagir NM, Sabahelkhier MK (2014) Hematological values in sheep fed a diet containing black cumin (Nigella sativa) seed oil. Int. J. Biochem. Res. Rev 4: 128-40.

26. El-ghousein SS (2010) Effect of some medicinal plants as feed additives on lactating ewe performance, milk composition, lamb growth and relevant blood items. Egypt. J. Anim. Prod 47: 37-49.

27. Saleh SA (2005) Effect of black seeds (Nigella sativa) supplementation on dairy ewes' performance. Arab J. Nucl. Sci. Appl 38: 298-306.

28. Allak MA (2013) Amelioration of heat stress by using some medicinal herbs and electrolytes and their effects on semen characterisics of Ossimi rams.

29. Khattab HM, El-Basiony AZ, Hamdy SM, Marwan AA (2011) Immune response and productive performance of dairy buffaloes and their offspring supplemented with black seed oil. Iran. J. Appl. Anim. Sci 1: 227-234.

30. Habeeb AAM, El-Tarabany AA (2012) Effect of Nigella sativa or curcumin on daily body weight gain, feed intake and some physiological functions in growing zaraibi goats during hot summer season. J. Radiat. Res. Appl. Sci 5: 60-78.
31.Ibrhim IE (2015) Effects of dietary herb supplements for ewes on milk contents and some biochemical parameter. Glob. J. Bio-Science Biotechnol 4: 209-212.

32. Retnani Y, Wiryawan KG, Khotijah L, Barkah NN, Gustian RA, et al. (2019) Growth performance, blood metabolites and nitrogen utilization of lambs fed with Nigella sativa meal. Pakistan J. Nutr 18: 247-253.

33. Borza C, Balint GS, Andoni M, Butur M (2013) Implications of oxidative stress in the pathogenesis of diabetic neuropathy. J. Food, Agric. Environ 13: $51-53$.

34. Nishikawa T, Edelstein D, Du XL, Yamagishi S, Matsumura T, et al. (2000) Normalizing mitochondrial superoxide production blocks three pathways of hyperglycaemic damage. Nature 404(6779): 787-790.

35. Dudko P, Junkuszew A, Bojar W, Milerski M, Szczepaniak K, et al. (2018) Effect of dietary supplementation with preparation comprising the blend of essential oil from Origanum vulgare (lamiaceae) and Citrus spp. (citraceae) on coccidia invasion and lamb growth. Ital. J. Anim. Sci 17: 57-65.

36. Sahoo N, Behura NC, Mishra J (2001) Effects of Immu-21 on certain blood biochemicals, milk, colostrum, body weight gain and livability in goats. Phytomedica 2: 69-76. 